\title{
Pembelajaran Argument Driven Inquiry Pada Materi Suhu dan Kalor Untuk Meningkatkan Kemampuan Argumentasi Ilmiah Siswa
}

\section{Argument Driven Inquiry Learning on Temperature and Heat Materials to Improve Students' Scientific Argumentation Abili}

\author{
Ratih Apri Sari $^{1}$, Bachrudin Musthafa ${ }^{2}$, \& Fazri Nur Yusuf ${ }^{3}$ \\ ${ }^{1}$ SMKN 1 Tembilahan Hulu, Kab. Indragiri Hilir, Riau, Indonesia \\ ${ }^{2,3}$ Universitas Pendidikan Indonesia, Bandung, Jawa Barat, Indonesia \\ ratihaprisari@upi.edu, dinmusthafa@upi.edu, fazrinuryusuf@upi.edu
}

Naskah diterima tanggal 23/06/2021, direvisi akhir tanggal 20/07/2021, disetujui tanggal 12/08/2021

\begin{abstract}
Abstrak
Pembelajaran berbasis proyek merupakan salah satu model pembelajaran yang direkomendasikan untuk digunakan dalam pembelajaran menurut kurikulum 2013. Pelaksanaan proses pembelajaran di Sekolah Menengah Kejuruan (SMK) memiliki karakteristik yang berbeda dengan pelaksanaan pembelajaran di Sekolah Menengah Atas (SMA). Guru SMK harus mampu mengembangkan model pembelajaran yang dapat menghasilkan aspek keterampilan kerja. Salah satu masalah paling kritis dalam proses belajar mengajar Bahasa Inggris di Sekolah Menengah Kejuruan adalah keengganan dan kreativitas guru yang kurang untuk menemukan cara agar pembelajaran lebih kreatif dan menyenangkan. Untuk mengetahui sejauh mana pemahaman siswa tentang suatu materi yang telah diajarkan dalam proses belajar mengajar, guru harus memberikan tugas kepada siswa. Penugasan dapat dilakukan dengan model Pembelajaran Berbasis Proyek (PjBL). Tujuan dari penelitian ini adalah untuk mengetahui bagaimana persepsi guru tentang pembelajaran berbasis proyek. Penelitian ini dilakukan dalam desain deskriptif kualitatif yang melibatkan tiga guru Bahasa Inggris SMK di Kabupaten Indragiri Hilir, Provinsi Riau sebagai responden. Penelitian ini menggunakan wawancara semi terstruktur sebagai instrumen pengumpulan data. Hasil analisis menunjukkan bahwa guru memiliki persepsi positif terhadap pembelajaran berbasis proyek. Dapat ditarik kesimpulan bahwa pembelajaran berbasis proyek perlu dilakukan oleh guru di kelas Bahasa Inggris sebagai salah satu model dalam proses belajar mengajar karena berfokus pada siswa.
\end{abstract}

Kata Kunci: Pembelajaran Berbasis Proyek, Persepsi Guru, dan Sekolah Menengah Kejuruan.

\begin{abstract}
Project-based learning is one of the recommended learning models to be used in learning according to the 2013 curriculum. The implementation of the learning process in Vocational High Schools has different characteristics from the implementation of learning in Senior High Schools. Vocational high school teachers must be able to develop learning models that can produce aspects of work skills. One of the most critical problems in teaching and learning English at Vocational High School is teachers' unwillingness and less creativity to find ways to make learning more creative and fun. To find out to what extent students understand the material that has been taught in the teaching and learning process, the teachers must give assignments to the students. The assignments can be done with the model Project-Based Learning. The aim of this study was to investigate how teachers' perceptions about project-based learning. This research was conducted in descriptive qualitative design which involved three vocational high school English teachers in Indragiri Hilir Regency, Riau Province as respondents. This research used the semi-structured interview as an instrument to collect the data. The result of the analysis showed that teachers have a positive perception of project-based learning. The conclusion can be drawn that project-based learning was needed to do by the teachers in the EFL classroom as one of the models in the teaching and learning process because its focus on student-centered.
\end{abstract}

Keywords: Project-Based Learning, Teachers' Perception, and Vocational High School.

How to cite (APA Style): Firdaos, I N., Puspitasari, I D., \& Permana, I. (2021). Pembelajaran Argument Driven Inquiry pada materi suhu dan kalor untuk meningkatkan kemampuan argumentasi ilmiah siswa. Jurnal Penelitian Pendidikan, 21 (2), 2021. 88-97. doi: https://doi.org/ 10.17509/jpp.v21i2.37134 


\section{PENDAHULUAN}

Salah satu keterampilan berpikir yang penting dikembangkan siswa adalah keterampilan berargumentasi (Mulyasa, 2014), Argumentasi memegang peran penting pada proses sains. Oleh karena itu, tujuan pembelajaran hanya memahirkan konsep dan pengetahuan sains, namun juga memfasilitasi siswa untuk terlibat aktif berargumentasi dalam pembelajaran sains (Kind et al., 2011). Pada kenyataannya pembelajaran sains kurang memberikan kesempatan bagi siswa untuk mengembangkan kemampuan berargumentasi. Pembelajaran yang memfasilitasi argumentasi siswa hanya sebatas tanya jawab, namun argumentasi dalam bentuk klaim, penyanggahan maupun penguatan masih kurang karena jarang melakukan diskusi kelas (Bulgren et al., 2014). Temuan ini senada dengan yang diperoleh Osborne (2010) yang menyatakan bahwa pembelajaran sains masih didominasi penjelasan dari guru dan hanya beberapa sekolah yang melibatkan pendekatan argumentasi menjadi dasar dalam pembelajarna sains. Hal tersebut berdampak pada keterampilan argumentasi siswa yang lemah, kesulitan dalam memberikan dukungan (backing) yang dapat melandasi pembenaran (warrant) untuk mendukung klaim yang akurat (Kaniawati \& Suhandi, 2014).

Keterampilan berargumentasi merupakan kemampuan mengkontekstualisasi pengetahuan untuk membenarkan suatu keputusan. Dengan demikian pengetahuan mempengaruhi keterampilan berargumentasi. Kualitas kemampuan kognitif sains sebanding dengan kualitas argumen yang dihasilkan siswa. Hal ini dikarenakan dalam proses berargumentasi, siswa mengelaborasi pengetahuan yang telah dimilikinya lalu merekonstruksinya untuk menyelesaikan permasalahan (Albe \& Gombert, 2012).

Penelitian sebelumnya mengenai kemampuan argumentasi oleh Handayani (2015) menyatakan bahwa sebagian siswa mampu mengeluarkan pernyataannya berupa klaim, namun tidak dapat memberikan bukti-bukti atau komponen argumen lainnya yang dapat mendukung pernyataan tersebut agar dikatakan benar. Penelitian lain yang dilakukan oleh Wahdan et al. (2017) sebagian besar peserta didik hanya memberikan data. Data tersebut yang tidak dilandasi dengan penjelasan secara ilmiah. Berdasarkan pemaparan penelitian terdahulu tersebut dapat ditarik kesimpulan bahwa masih lemahnya kemampuan argumentasi ilmiah pada siswa. Salah satu alternatif model pembelajaran yang dikembangkan untuk melatih kemampuan argumentasi ilmiah adalah model pembelajaran ArgumentDriven Inquiry (ADI) (Walker \& Sampson, 2013).

ADI merupakan pembelajaran berorientasi inkuiri yang menekankan pada kegiatan berargumentasi yang mampu melatih siswa berargumentasi. Menurut Venville dan Dawson \& Venville (2010), untuk mengembangkan keterampilan berargumentasi, guru perlu menggunakan strategi yang tepat. Untuk itu-kemampuan berargumentasi atau kemampuan menyusun argumen dilatihkan dan dibiasakan dalam pembelajaran sains agar dapat meningkatkan keterampilan argumentasi siswa.

\section{METODE PENELITIAN}

Metode penelitian yang digunakan adalah Quasi Experiment dengan Pretest-Posttest Control Group Design (Fraenkel \& Wallen, 2012). Penelitian menggunakan dua kelas; yaitu kelas eksperimen yang diberi treatment (perlakuan) dan kelas pembanding yang diberi treatment berbeda dari kelas eksperimen. Penelitian dilakukan terhadap 60 siswa kelas IX SMPN L Kab. Sukabumi pada masa pandemi Covid-19. Adapun tujuan dari penelitian untuk mengetahui perbedaan kemampuan argumentasi ilmiah siswa dengan menggunakan model ADI.

Data dikumpulkan menggunakan instrumen berupa soal tes berbentuk uraian untuk mengukur peningkatan kemampuan argumentasi berjumlah 10 soal yang sudah dinyatakan valid oleh ahli. Soal memenuhi indikator pembelajaran pada materi suhu dan kalor, serta indikator kemampuan argumentasi yaitu klaim (claim), data (data), bukti (fact), dan dukungan (backing). Kualitas argumen tertulis siswa 
dapat dilihat berdasarkan indikator argumentasi yang diadaptasi dari Toulmin Argumentation Pattern (TAP) serta kriterianya Erduran, et al. (2004). Kerangka analitik untuk menilai kualitas level argumentasi disajikan pada Tabel 1.

Table 1. Kerangka Analitik untuk Menilai Kualitas level Argumentasi

\begin{tabular}{cl}
\hline Level & \multicolumn{1}{c}{ Kriteria } \\
\hline 1 & Argumentasi memiliki argumen yang terdiri dari klaim (claim) sederhana melawan klaim (claim) lainnya. \\
2 & $\begin{array}{l}\text { Argumentasi memiliki argumen yang terdiri dari klaim (claim) melawan klaim (claim) lain disertai data } \\
\text { (data), jaminan (warrant) atau dukungan (backing), tapi tidak mengandung sanggahan apapun }\end{array}$ \\
3 & $\begin{array}{l}\text { Argumentasi memiliki argumen yang terdiri dari klaim (claim) melawan klaim (claim) claim) lain disertai } \\
\text { data (data), jaminan (warrant) atau dukungan (backing), serta sanggahan (rebuttal) yang lemah. }\end{array}$ \\
4 & $\begin{array}{l}\text { Argumentasi memiliki argumen yang terdiri dengan sanggahan (rebuttal) yang jelas dan mengandung } \\
\text { beberapa klaim (claim) disertai data (data), jaminan (warrant) atau dukungan (backing). }\end{array}$ \\
5 & Argumentasi menampilkan argumen yang diperluas dengan lebih dari satu sanggahan (rebuttal) yang jelas \\
\hline
\end{tabular}

Sumber : Erduran, et al. (2004)

\section{HASIL DAN PEMBAHASAN Hasil}

Argumentasi seseorang dapat dilakukan secara lisan dan tertulis. Argumentasi ilmiah yang diukur dalam penelitian ini merupakan argumentasi ilmiah secara tertulis. Hasil perbedaan dan peningkatan kemampuan argumentasi disajikan dalam Gambar 1.

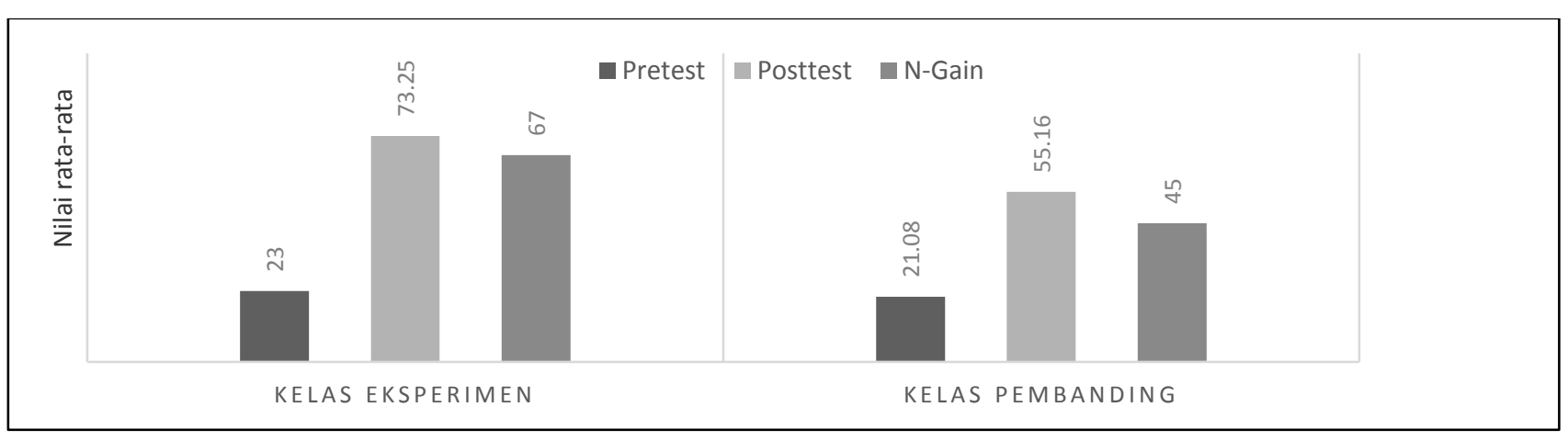

Gambar 1. Perbandingan nilai rata-rata pretest, posttest, dan N-gain kemampuan argumentasi siswa

Gambar 1 menunjukkan nilai rata-rata pretest antara kelas eksperimen dan kelas pembanding memperlihatkan nilai rata-rata dengan rentang yang tidak begitu jauh. Hal ini dapat bermakna bahwa siswa pada kelas eksperimen maupun kelas pembanding memiliki kemampuan berargumentasi awal yang sama pada materi suhu dan kalor. Gambar 1 mengungkap bahwa nilai rata-rata posttest pada kemampuan berargumentasi kelas eksperimen lebih besar dari pada nilai rata-rata posttest kemampuan berargumentasi kelas pembanding. Adanya peningkatan dan perbedaan kemampuan berargumentasi yang jelas baik pada kelas eksperimen yang mengikuti pembelajaran model ADI maupun pada kelas pembanding yang mengikuti pembelajaran konvensional. Selanjutnya, temuan di atas mengungkap bahwa $N$-gain kelas eksperimen lebih tinggi dibandingkan kelas. Oleh karena itu dapat disimpulkan bahwa penerapan pembelajaran model ADI pada kelas eksperimen memiliki dampak yang lebih besar dalam menstimulasi peningkatan kemampuan berargumentasi siswa. Level argumentasi siswa dapat dilihat pada Gambar 2. 


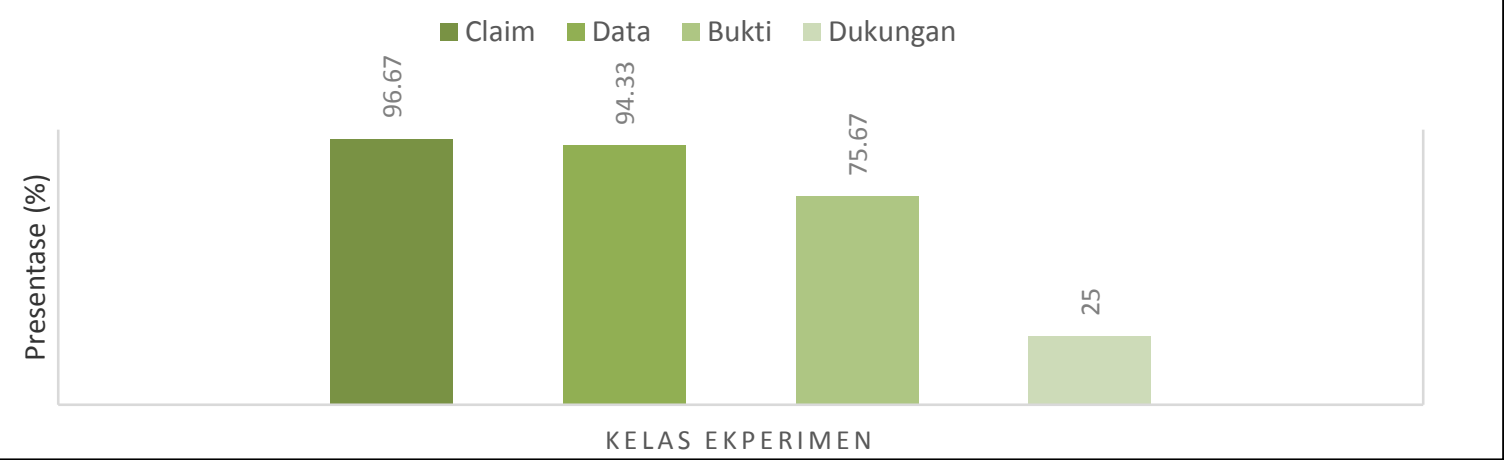

Gambar 2. Grafik Level Argumentasi Siswa Setelah Pembelajaran Dengan Menggunakan Model ADI.

Berdasarkan data Gambar 2. kemampuan argumentasi siswa, berdasarkan indikator argumentasi menunjukkan klaim (claim) memiliki persentase paling tinggi, yaitu sebanyak 96,67\% indikator data 94,33\%, indikator bukti (warrant) sebanyak 75,67\% dan yang memiliki persentase yang paling sedikit adalah indikator dukungan (backing) sebanyak 25\%. Siswa pada level 1 menjawab dengan menyertakan klaim saja, klaim yang dijawab juga benar. Indikator klaim menjADI persentase terbesar, karena dalam semua tingkatan level juga mengandung klaim. Erduran et al., (2004) mengkriteriakan level 1 dengan argumen yang terdiri dari klaim sederhana melawan klaim lainnya. Menurut Erduran et al., (2004), kemampuan argumentasi level 2 terdiri atas klaim disertai data, penjamin, atau pendukung. Siswa sudah menyertakan bukti atau dukungan terhadap klaim yang sudah dipilihnya, agar klaim tersebut terbukti benar. Hal tersebut didukung dengan pemahaman siswa mengenai materi pelajaran suhu dan kalor dan pengalaman dilingkungan sekitar yang relevan sehingga siswa dapat berargumentasi dan mengemukakan pendapatnya dengan percaya diri.

Siswa pada level 3, menurut Erduran et al., (2004) argumen dari klaim melawan klaim lain disertai data, jaminan, atau pendukung, serta sanggahan yang lemah. Sanggahan yang lemah merupakan sanggahan yang dibuat tanpa menggunakan bukti apapun (Demircioglu \& Ucar, 2015). Berdasarkan jawaban pada level 3, siswa menuliskan sanggahan, namun belum dianggap benar, tepat atau sesuai. Hal ini dikarenakan pada level ini tidak hanya pemahaman siswa yang dituntut dalam berargumentasi tetapi siswa diajak untuk membuat sebuh sanggahan yang berdasarkan teori dan fakta yang ada terhadap sebuah fenomena. Menurut Noviyanti et al., (2019), argumen pada level ini sudah cukup namun masih perlu dikembangkan.

Siswa pada level 4, menurut Erduran et al., (2004) argumen memiliki sanggahan yang jelas dan mengandung beberapa klaim disertai data, jaminan atau dukungan. Sanggahan tersebut sudah dianggap benar berdasarkan bukti dan alasan yang logis, sedangkan Pada level 5, menurut Erduran et al., (2004) argument sudah yang komplek disertai dengan lebih dari satu sanggahan. Persentase argumentasi siswa level 4 dan level 5 lebih rendah dibanding persentase level lainnya. Hal ini dikarenakan pada level ini siswa dituntut perpikir kritis terhadap sebuah fenomena yang ada membuat semua kemungkinan dari sebuah fakta dan pengalaman siswa terhadap materi sangat berperan penting dalam level ini. Selanjutnya diberikan pula angkat pada siswa terhadap penggunaan model ADI yang dapat dilihat pada Tabel 2. 
Tabel 2. Angket Tanggapan Siswa Terhadap Pembelajaran Model ADI.

\begin{tabular}{|c|c|c|c|c|c|}
\hline \multirow{2}{*}{ No } & \multirow{2}{*}{ Pernyataan } & \multicolumn{4}{|c|}{ Tanggapan Siswa (\%) } \\
\hline & & SS & $\mathbf{S}$ & TS & STS \\
\hline 1 & $\begin{array}{l}\text { Pembelajaran } A D I \text { membantu dalam menyelesaikan masalah } \\
\text { fenomena suhu dan kalor dengan kegiatan praktikum }\end{array}$ & 23 & 67 & 10 & 0 \\
\hline 2 & $\begin{array}{l}\text { Kegiatan mengamati dan mengobservasi } \\
\text { dalam pembelajaran ADI membantu dalam mengidentifikasi } \\
\text { masalah femomena suhu dan kalor. }\end{array}$ & 33 & 57 & 10 & 0 \\
\hline 3 & $\begin{array}{l}\text { Kegiatan mengamati dan mengobservasi dalam pembelajaran } \\
A D I \text { membantu dalam membedakan komponen suhu dan kalor. }\end{array}$ & 30 & 70 & 0 & 0 \\
\hline 4 & $\begin{array}{l}\text { Kegiatan diskusi kelompok dalam pembelajaran } A D I \text { membantu } \\
\text { dalam merumuskan masalah dan membentuk argument yang tepat } \\
\text { Kegiatan mengamati dan mengobservasi dalam pembelajaran }\end{array}$ & 27 & 67 & 0 & 7 \\
\hline 5 & $\begin{array}{l}A D I \text { membantu dalam pengambilan hipotesis fenomena suhu dan } \\
\text { kalor. }\end{array}$ & 40 & 60 & 0 & 0 \\
\hline 6 & $\begin{array}{l}\text { Kegiatan mengamati dan mengobservasi dalam pembelajaran } \\
A D I \text { membantu dalam menentukan klaim pada fenomena suhu } \\
\text { dan kalor }\end{array}$ & 33 & 67 & 0 & 0 \\
\hline 7 & $\begin{array}{l}\text { Kegiatan diskusi kelompok membantu dalam pembelajaran } A D I \\
\text { dalam menjelaskan data hubungan fenomena dilingkungan sekitar } \\
\text { dengan suhu dan kalor. }\end{array}$ & 30 & 63 & 7 & 0 \\
\hline 8 & $\begin{array}{l}\text { Kegiatan diskusi kelompok dalam pembelajaran } A D I \text { membantu } \\
\text { dalam menemukan data argumentasi berdasarkan fenomena suhu } \\
\text { dan kalor }\end{array}$ & 20 & 67 & 13 & 0 \\
\hline 9 & $\begin{array}{l}\text { Kegiatan diskusi kelompok dalam pembelajaran Argument } \\
\text { driven Inquiry membantu dalam menemukan bukti/fakta } \\
\text { argumentasi fenomena dilingkungan sekitar dengan suhu dan } \\
\text { kalor. }\end{array}$ & 43 & 50 & 0 & 7 \\
\hline 10 & $\begin{array}{l}\text { Kegiatan diskusi kelompok membantu saya dalam memprediksi } \\
\text { Argument atau pengaruh dari jawaban (solusi) terbaik jika } \\
\text { diterapkan untuk mengatasi suatu permasalahan. }\end{array}$ & 33 & 57 & 10 & 0 \\
\hline 11 & $\begin{array}{l}\text { Kegiatan diskusi dalam pembelajaran } A D I \text { membantu dalam } \\
\text { membuat jawaban atau solusi terkait masalah suhu dan kalor. }\end{array}$ & 40 & 50 & 7 & 3 \\
\hline 12 & $\begin{array}{l}\text { Kegiatan diskusi kelompok } A D I \text { membantu dalam menentukan } \\
\text { jawaban atau argumentasi penyelesaian masalah terbaik tentang } \\
\text { suhu dan kalor }\end{array}$ & 40 & 50 & 10 & 0 \\
\hline & Rata-rata & 32,8 & 60,3 & 5,6 & 1,4 \\
\hline
\end{tabular}

Berdasarkan Tabel 2 apat diketahui bahwa tanggapan siswa yang menunjukkan bahwa pembelajaran model ADI membantu dalam mengembangkan kemampuan berargumentasi dari 6 item pernyataan antara lain pernyataan pada item nomor 4, 6, 7, 8, 9 dan 10. Pada pernyataan item nomor 4 dan nomor 10 sebagian besar siswa mengungkapkan bahwa kegiatan pembelajaran dengan model ADI membantu mereka memprediksi dan membuat argumentasi suatu permasalahan dengan tepat, dengan memberikan respon setuju sebesar 67\% (item nomor 4) dan 57\% (item nomor 10). Meskipun demikian dapat diungkapkan bahwa terdapat sekitar $7 \%$ siswa memberikan respon tidak setuju pada item nomor 7 yang menyatakan kegiatan diskusi kelompok kurang membantu dalam pembelajaran ADI menjelaskan data hubungan fenomena di lingkungan sekitar dengan suhu dan kalor. Namun, disisi lain banyak siswa yang mengungkapkan bahwa kegiatan mengamati dan mengobservasi dalam pembelajaran ADI membantu dalam menentukan klaim pada fenomena suhu dan kalor, memberikan respon setuju sebesar 67\% dan sangat setuju 33\% (item nomor 6). Sementara itu persentase respon setuju sebesar $61 \%$ pada item nomor 8 mennjukkan bahwa kegiatan diskusi kelompok dalam pembelajaran model ADI membantu dalam menemukan data argumentasi berdasarkan fenomena suhu e-ISSN: 2541-4135 I p-ISSN: 1412-565 X

Copyright (c) authors, 2021 
dan kalor. Sedangkan pada item nomor 9 menujukan persentase respon sebesar setuju $50 \%$ dan sangat satuju $43 \%$ dengan demikan model ADI menurut para siswa dapat membantu dalam menemukan bukti atau fakta. argumentasi fenomena di lingkungan sekitar dengan suhu dan kalor.

Tabel 2 juga memberikan informasi bahwa sebagian besar siswa mengungkapkan pembelajaran model ADI membantu mereka dalam mengdentfkasi, membedakan komponen, hipotesi, solusi dan penyelesaan masalah terkait fenomena suhu dan kalor, yang dapat dilihat dari tanggapan mereka pada 5 item pernyataan antara lain pada item pernyataan nomor 2, 3, 5, 11 dan 12 . Hal ini didukung dengan banyaknya siswa yang memberikan respon setuju sebesar $57 \%$ dan $22 \%$ pada item nomor 2 bahwa kegiatan mengamati dan mengobservasi dalam pembelajaran ADI membantu dalam mengidentifikasi masalah femomena suhu dan kalor. Disusul dengan item nomor 3 yang menunjukkan bahwa siswa memberikan respon setuju 70\% dan sangat setuju 30\% yang dapat diartikan bahwa kegiatan mengamati dan mengobservasi dalam pembelajaran ADI membantu dalam membedakan komponen suhu dan kalor. Begitu juga dengan item nomor 5 menunjukkan bahwa sebagian besar siswa memberikan respon setuju sebesar $60 \%$ yang dapat diartikan kegiatan mengamati dan mengobservasi dalam pembelajaran Selain angket tanggapan terhadap model ADI di sebar pula angket tanggapan siswa terhadap keinginan untuk menerapkan pembelajaran model ADI pada materi IPA lain. Adapun rekapitulasi tanggapan secara keseluruhan disajikan pada Tabel 3.

Tabel 3. Tanggapan Siswa Terhadap Pembelajaran model ADI Untuk Diterapkan Pada Pembelajaran Materi IPA Lain.

\begin{tabular}{|c|c|c|c|c|c|}
\hline \multirow[t]{2}{*}{ No } & \multirow[t]{2}{*}{ Pernyataan } & \multicolumn{4}{|c|}{ Tanggapan Siswa (\%) } \\
\hline & & SS & $\mathbf{S}$ & TS & SS \\
\hline 1 & $\begin{array}{l}\text { Jika mempelajari materi IPA lain, } \\
\text { saya akan selalu siap melakukan } \\
\text { kegiatan Pembelajaran Model } \\
\text { Argumentdriven Inquiry }(A D I)\end{array}$ & 27 & 67 & 7 & $\mathbf{0}$ \\
\hline 2 & $\begin{array}{l}\text { Akan lebih baik mempelajari materi } \\
\text { IPA selain suhu dan kalor di lakukan } \\
\text { di luar ruangan. }\end{array}$ & 33 & 57 & $\mathbf{0}$ & 10 \\
\hline 3 & $\begin{array}{l}\text { Lembar kerja yang rinci dan } \\
\text { terfokus membantu lebih banyak } \\
\text { belajar tentang materi suhu dan } \\
\text { kalor }\end{array}$ & 33 & 60 & 7 & $\mathbf{0}$ \\
\hline & Rata-rata & 31,1 & 61,1 & 4,4 & 3,3 \\
\hline
\end{tabular}

Tabel 3 memberikan informasi bahwa sebagian besar siswa ingin menerapkan kembali Pembelajaran model ADI pada materi IPA lain dengan persentase respon setuju sebesar $61,1 \%$ dan sangat setuju 31,1\%. Hal ini didukung oleh banyaknya siswa yang memberikan respon setuju sebesar 67\% pada item nomor 1 yakni bahwa mereka akan selalu siap jika guru mengajak untuk mempelajari materi IPA selain suhu dan kalor dengan menyelenggarakan pembelajaran model ADI. Tidak hanya itu mereka juga berharap bahwa ketika belajar materi IPA selain suhu dan kalor, guru dapat mengajak mereka untuk melakukan pembelajaran di luar ruangan. Hal tersebut didukung dengan sebagian besar siswa memberikan respon setuju 57\% dan 33\% sangat setuju pada item nomor 2. Meskipun demikian, terdapat sekitar $10 \%$ siswa yang merasa tidak mengharapkan pembelajaran menggunakan model ADI ketika guru mengajar materi IPA . Hal ini juga berkaitan dengan item nomor 3 yang mengungkapkan bahwa terdapat sekitar 7\% memberikan respon kurang setuju, yang dapat diartikan bahwa siswa kurang banyak belajar tentang materi suhu dan kalor ketika diberikan lembar kerja yang mengenai langkahlangkah kerja yang siswa harus lakukan, namun disisi lain, siswa sebagian besar mengungkapkan bahwa mereka lebih banyak belajar tentang materi suhu dan kalor ketika diberikan lembar kerja dengan 
memberikan respon setuju sebesar $60 \%$ dan 33\% sangat setuju. Kemampuan berargumentasi yang diperoleh tidak terjadi secara kebetulan, melainkan sebagai hasil dari pengalaman siswa selama mengikuti pembelajaran yang dapat dipengaruhi juga oleh variabel lain (Patrick, 2010). Salah satu faktor penting yang berdampak pada peningkatan kemampuan berargumentasi siswa adalah pengalaman sebelumnya yang dimiliki oleh siswa tentang topik suhu dan kalor atau dengan kata lain pengetahuan konsep awal yang dimiliki siswa tentang materi suhu dan kalor. Tidak mengherankan bahwa kemampuan berargumentasi baik pada kelas eksperimen maupun pada kelas pembanding menunjukkan adanya peningkatan. Hal ini dikarenakan bahwa siswa yang berada di tingkat sekolah menengah pertama telah memiliki pengetahuan awal tentang suhu, sebab saat mereka telah dikenalkan dan telah belajar tentang konsep suhu dan kalor di tingkat sekolah dasar dalam pembelajaran IPA. Selain itu, faktor lain yang dapat memengaruhi peningkatan kemampuan berargumentasi siswa pada materi suhu dan kalor baik pada kelas eksperimen maupun kelas pembanding adalah lokasi pembelajaran di lapangan (Patrick, 2010). Hal ini karena sebagian besar tempat tinggal siswa dekat dengan lingkungan pembelajaran.

\section{Pembahasan}

Data pretest dan posttest kemampuan berargumentasi yang telah dianalisis secara statistik menunjukan perbedaan kemampuan berargumentasi antara kelas eksperimen dan kelas pembanding.hal ini menunjukan bahwa model ADI dapat meningkatkan kemampuan berargumentasi siswa. Pembelajaran model ADI pada penelitian ini juga tidak hanya sekedar mengamati komponen suhu dan kalor yang terdapat di lingkungan, namun mereka harus berupaya secara maksimal untuk membuat rumusan masalah dan memecahkan permasalahan dengan mengungkapkan argument yang tepat pada setap fenomena suhu dan kalor. Hasil penelitian Asra et al., (2018) mengungkapkan bahwa menyelenggarakan pembelajaran yang dikombinasikan dengan investigasi dalam proses pembelajarannya siswa tidak hanya sekedar mengamati objek atau fenomena konten pelajaran, tetapi juga akan menggunakan pemikirannya dalam memilah informasi yang diterima, memprioritaskan informasi dan mencari hubungan antar informasi, bahkan sampai mencari argumen yang mendukung alasan sebelum akhirnya merangkum informasi yang diterima menjADI sebuah pengetahuan baru Oleh karena itu pembelajaran model ADImampu berkontribusi dalam meningkatkan kemampuan berargumentasi siswa tentang materi suhu dan kalor.

Pengalaman pertama siswa dalam melakukan pembelajaran model ADIke lingkungan alamiah juga ikut berkontribusi dalam meningkatkan kemampuan berargumentasi. Hal ini disebabkan karena di lokasi pembelajaran yang dianggap baru oleh sebagian besar siswa, intervensi minimal mampu menghasilkan perubahan yang signifikan dalam kemampuan siswa untuk berpikir kritis tentang suatu fenomena atau objek yang belum pernah mereka lihat sebelumnya. Tidak hanya itu, selama siswa berada di lingkungan belajar yang dianggap baru, mereka akan lebih antusias dalam mengamati, menginterpretasi, mengevaluasi, mengasosiasikan, membandingkan dan berusaha memecahkan masalah (Kisida et al., 2015). Seperti halnya dalam penelitian ini, pada pembelajaran model ADI siswa terlihat antusias karena menggunakan lngkungan sekitar sebagai lokasi untuk mendapatkan pengalaman belajar tentang suhu dan kalor, sebab meskipun mereka sering berkunjung ke lokasi yang dijadikan sebagai pembelajaran di lapangan, mereka hanya sekedar menikmati alam saja dan belum pernah berinteraksi bahkan merasakan dan menyentuh komponen yang ada di lingkungan tersebut. Oleh karena hal itu, ditekankan manfaat paling penting dari model ADI terletak pada fakta dasar bahwa pembelajaran model ADImenyediakan suatu cara yang stematis bagi siswa untuk belajar berargumentasi dengan benar berdasarkan aspek yang ada. Bahkan, pembelajaran model ADI juga memberi kesempatan kepada siswa untuk menggunakan berbagai indera dalam proses belajar IPA, 
sehingga dapat membuat topik atau konsep dan prinsip yang sedang dipelajari dan diajarkan akan menjadi lebih jelas dan memiliki retensi yang lebih baik.

Sebagaimana diketahui bahwa peningkatan nilai pretest dan posttest kemampuan berargumentasi yang diperoleh tidak terjadi secara kebetulan, melainkan sebagai hasil dari pengalaman siswa selama mengikuti pembelajaran yang dapat dipengaruhi juga oleh variabel lain (Patrick, 2010). Salah satu faktor penting yang berdampak pada peningkatan kemampuan berargumentasi siswa adalah pengalaman sebelumnya yang dimiliki oleh siswa tentang topik suhu dan kalor atau dengan kata lain pengetahuan konsep awal yang dimiliki siswa tentang materi suhu dan kalor. Tidak mengherankan bahwa kemampuan berargumentasi baik pada kelas eksperimen maupun pada kelas pembanding menunjukkan adanya peningkatan. Hal ini dikarenakan bahwa siswa yang berada di tingkat sekolah menengah pertama telah memiliki pengetahuan awal tentang suhu, sebab saat mereka telah dikenalkan dan telah belajar tentang konsep suhu dan kalor di tingkat sekolah dasar dalam pembelajaran IPA. Selain itu, faktor lain yang dapat memengaruhi peningkatan kemampuan berargumentasi siswa pada materi suhu dan kalor baik pada kelas eksperimen maupun kelas pembanding adalah lokasi pembelajaran di lapangan.

\section{KESIMPULAN}

Terdapat perbedaan kemampuan argumentasi siswa menggunakan pembelajaran ADI. Berdasarkan hasil uji $N$-Gain mengungkap bahwa peningkatan kemampuan berargumentasi pada kelas eksperimen dan pembanding memiliki peningkatan pada kategori sedang. Namun diperoleh nilai ratarata kelas eksperimen sebesar (n-gain $=0,67$ ) lebih besar dari pada peningkatan kemampuan berargumentasi yang diperoleh kelas pembanding. Hal tersebut menunjukan bahwa pembelajaran ADI memilki nilai rata-rata yang lebih besar dibandingkan kelas yang menggunakan pembelajaran konvensional terhadap peningkatan argumentasi siswa walaupun sama-sama pada kategori "sedang". Sebagian besar siswa masih berada di level 1 sampai level 2, yang berarti argumen tersebut masih rendah. Siswa pada level tersebut sudah dapat menyatakan klaim (claim) berdasarkan data (data), jaminan (warrant) atau dukungan (backing). Kemampuan argumentasi siswa yang masih rendah tersebut harus ditingkatkan kembali mengingat pentingnya kemampuan tersebut dalam mendukung capaian keterampilan abad 21. Sebagian besar siswa menginginkan pembelajaran ADI dapat dipakai atau diaplikasikan pada materi IPA yang lain.

Peneliti menyarankan untuk melaksanakan pembelajaran yang melibatkan siswa secara aktif dalam melatih kemampuan argumentasi. Salah satunya dengan menerapkan model pembelajaran. Model pembelajaran yang dipandang mampu melatih kemampuan argumentasi ilmiah adalah model argumentasi berbasis inkuiri karena siswa dapat menyampaikan argumennya berdasarkan penyelidikan ilmiah yang telah dilakukan.

\section{DAFTAR PUSTAKA}

Albe, V., \& Gombert, M.-J. (2012). Students' communication, argumentation and knowledge in a citizens' conference on global warming. Cultural Studies of Science Education, 7(3), 659-681. https://doi.org/10.1007/s11422-012-9407-1 
Asra, H. S., Diana, S., \& Amprasto. (2018). Implementation of inquiry-based field trip method to improve critical thinking and problem solving skills of students on plantae topic. International Conference on Mathematics and Science Education "Promoting 21st Century Skills Through Mathematics and Science Education,” 103-107. http://science.conference.upi.edu/proceeding/index.php/ICMScE/issue/view/3

Bulgren, J. A., Ellis, J. D., \& Marquis, J. G. (2014). The Use and Effectiveness of an Argumentation and Evaluation Intervention in Science Classes. Journal of Science Education and Technology, 23(1), 82-97. https://doi.org/10.1007/s10956-013-9452-x

Dawson, V. M., \& Venville, G. (2010). Teaching Strategies for Developing Students' Argumentation Skills About Socioscientific Issues in High School Genetics. Research in Science Education, 40(2), 133-148. https://doi.org/10.1007/s11165-008-9104-y

Demircioglu, T., \& Ucar, S. (2015). Investigating the effect of argument-driven inquiry in laboratory instruction. Kuram ve Uygulamada Egitim Bilimleri, 15(1), 267-283. https://doi.org/10.12738/estp.2015.1.2324

Erduran, S., Simon, S., \& Osborne, J. (2004). TAPping into argumentation: Developments in the application of Toulmin's Argument Pattern for studying science discourse. Science Education, 88(6), 915-933. https://doi.org/10.1002/sce.20012

Fraenkel, J.R., Wallen, N. . (2012). How to Design and Evaluate Research in Education (8th ed.). McGraw-Hill.

Mulyasa. H. E. (2014). Pengembangan dan Implementasi Kurikulum 2013 (Anang Solihin Wardan (ed.)). Remaja Rosdakarya.

Handayani, P. (2015). Analisis argumentasi peserta didik kelas x sma muhammadiyah 1 palembang dengan menggunakan model argumentasi toulmin. Jurnal Inovasi dan Pembelajaran Fisika, 2(1), 60-68.

Ika Noviyanti, N., Rosyadah Mukti, W., Dahlia Yuliskurniawati, I., Mahanal, S., \& Zubaidah, S. (2019). Students' scientific argumentation skills based on differences in academic ability. Journal of Physics: Conference Series, 1241(1). https://doi.org/10.1088/1742-6596/1241/1/012034

Kaniawati, I., \& Suhandi, A. (2014). PENERAPAN MODEL PEMBELAJARAN PEMBANGKIT IMPLEMENTATION OF GENERATE ARGUMENT INSTRUCTIONAL MODEL USING SCIENTIFIC METHOD TO INCREASE THE COGNITIVE ABILITIES AND. 10(2), 104-116. https://doi.org/10.15294/jpfi.v10i2.3347

Kind, P., Kind, V., Hofstein, A., \& Wilson, J. (2011). Peer Argumentation in the School Science Laboratory-Exploring effects of task features. International Journal of Science Education, 33, 2527-2558. https://doi.org/10.1080/09500693.2010.550952

Kisida, B., Bowen, D. H., \& Greene, J. P. (2015). Measuring Critical Thinking: Results From an Art Museum Field Trip Experiment. Journal of Research on Educational Effectiveness, 9(March), 171-187. https://doi.org/10.1080/19345747.2015.1086915

Manni, A., Ottander, C., Sporre, K., \& Parchmann, I. (2013). Perceived learning experiences regarding Education for sustainable development: -within Swedish outdoor education trADItions. NorDiNa: Nordic Studies in Science Education, 9(2), 187-205.

Orion, N., \& Hofstein, A. (1994). Factors that influence learning during a scientific field trip in a natural environment. Journal of Research in Science Teaching, 31(10), 1097-1119. https://doi.org/10.1002/tea.3660311005

Osborne, J. (2010). Arguing to Learn in Science: The Role of Collaborative, Critical Discourse. Science, 328(5977), 463 LP - 466. https://doi.org/10.1126/science.1183944

Patrick, A. O. (2010). Effects of Field Studies on Learning Outcome in Biology. Journal of Human 
Ecology, 31(3), 171-177. https://doi.org/10.1080/09709274.2010.11906312

Wahdan, W. Z., Sulistina, O., \& Sukarianingsih, D. (2017). Analisis Kemampuan Berargumentasi Ilmiah Materi Ikatan Kimia Peserta Didik Sma, Man, Dan Perguruan Tinggi Tingkat I. J-PEK (Jurnal Pembelajaran Kimia), 2(2), 30-40. https://doi.org/10.17977/um026v2i22017p030

Walker, J. P., \& Sampson, V. (2013). Argument-Driven Inquiry: Using the Laboratory To Improve Undergraduates' Science Writing Skills through Meaningful Science Writing, Peer-Review, and Revision. Journal of Chemical Education, 90(10), 1269-1274. https://doi.org/10.1021/ed300656p 